\title{
Effects of Silica Sol on Structure and Properties of Core-Shell Silicon-Acrylic Materials
}

\author{
Xuan Li, Yiding Shen, Haihua Wang, Guiqiang Fei \\ Key Laboratory of Auxiliary Chemistry and Technology for Chemical Industry, Ministry of Education, \\ Shanxi University of Science and Technology, Xi'an, China \\ Email: lixuan1552@yahoo.cn, lixuan1552@gmail.com
}

Received February 10, 2012; revised March 13, 2012; accepted April 10, 2012

\begin{abstract}
Silica sol prepared by sol-gel method was introduced into poly(butyl acrylate) (PBA)/poly(butyl acrylate-styrenemethacryloxypropyl trimethoxysilane) (PSBM) core-shell emulsions to prepare a series of paper surface sizing agents. The rheological measurement indicated that PSBM emulsions exhibited shear-thinning behavior, and the phenomena became more pronounced with increasing silica sol concentration. Dynamic mechanical analysis (DMA) demonstrated that the stronger interfacial interaction between silica sol and polymer matrix, but microphase separation took place with excess silica sol. Thereby the tensile strength and thermal stability of emulsion films were increased with desirable silica sol concentration, and when silica sol concentration was greater than $6 \mathrm{wt} \%$, the tensile strength leveled off and the decomposition temperature decreased from $351.19^{\circ} \mathrm{C}$ to $331.63^{\circ} \mathrm{C}$. The degree of crystallinity increased from $5.12 \%$ to $10.98 \%$ with $4 \%$ silica sol addition, resulting in enhanced rigidity of films. Furthermore, the interaction between polymer and fiber was improved with certain amount of silica sol, resulting in improved sizing degree, ring crush strength, surface strength and folding strength. However, excessive crosslinking will be harmful for the properties of sized paper.
\end{abstract}

Keywords: Core-Shell Emulsion; Silica Sol; Thermal Property; Mechanical Property; Surface Sizing

\section{Introduction}

Incorporation of inorganics into organic polymers via covalent bonding has gotten particular attention since the hybrid materials will have a controllable combination of properties of both organic polymers and inorganics [1-4]. Nano-silica, as one of inorganic materials, was always employed to blend with polymer to obtain hybrid materials, due to its lower surface free energy, high hardness, good wear resistance, thermal stability and durability [1].

In general, silica/polymer composite materials were prepared by mechanical mixing, molding techniques and sol-gel method. Sol-gel method was one of the most important ways to synthesize hybrid materials composed of polymer and $\mathrm{SiO}_{2}$ owing to its mild processing condition [5-9]. In addition, polymer having functional groups that have specific interactions with silanol groups can prevent the macrophase separation and obtain composites with high homogeneity and optical transparency [9-11]. It is also reported that mechanical properties and macrophase separation can be improved with increasing hydrophilicity and polarity of polymer matrix [9]. However, hybrids obtained from traditional sol-gel synthesis techniques have high volume shrinkage.
Nano-silica particles have a number of hydroxyl groups on the surface, resulting in strong interfacial interactions between nano-silica particles and polymer matrix [12]. However, aggregations among nano-silica particles take place simultaneously $[13,14]$. It is difficult for nanoinorganic particles to disperse in polymer matrix at nano scale $[15,16]$. Using nano-silica prepared by hydrolytic polymerization of tetraethoxysilane (TEOS) through sol-gel process has been demonstrated to be a good method to overcome the above-mentioned shortcomings $[17,18]$.

The alkoxysilanes, as bifunctional substances, are also intensively adopted to increase the interaction and miscibility between filler and polymer matrix [19]. In general, silica particles modified with silane coupling agents are always blended with polymer emulsion to improve the interaction between polymer and silica particles [20,21]. The route to synthesize stable poly(butyl acrylate) (PBA)/poly(butyl acrylate-styrene-methacryloxypropyl trimethoxysilane) (PSBM) core-shell emulsion using polymerisable maleate surfactant has been studied in our previous study [22], as well as the effects of silane coupling agent [23]. However, the introduction of silica sol may induce phase separation which greatly influenced the 
mechanical properties, thermal stability and water resistance of emulsion films. Therefore, it was indispensible to systematically investigate how the change in silica sol concentration controlled the properties of the emulsions and films.

The main objective of this paper is to investigate the approach to improve the mechanical properties and water resistance of the emulsions films and corresponding sized paper through controlling interactions among polymer chains and fibers. In this paper, silica sol prepared by sol-gel method was directly introduced into poly(butyl acrylate) (PBA)/poly(butyl acrylate-styrene-methacryloxypropyl trimethoxysilane) (PSBM) core-shell emulsion to obtain paper surface sizing agent. Effects of silica sol concentration on rheological behavior, static and dynamic mechanical properties, crystallinity, and thermal properties of emulsion films were studied. In addition, the properties of papers which were sized with PSBM emulsions of different silica sol concentration, such as sizing degree, surface strength, crush strength and folding strength, were investigated.

\section{Experimental}

\subsection{Materials}

3-Methacryloxypropyl trimethoxysilane (MPTS) (Wuhan Institute of Applied Technology, China) were used as received. Sodium bisulfite $\left(\mathrm{NaHSO}_{3}\right)$, potassium persulfate, ferric chloride, ammonium thiocyanate and aqueous ammonia $\left(\mathrm{NH}_{3} \cdot \mathrm{H}_{2} \mathrm{O}\right)$ from Tianjin Dengfeng Chemical Reagent Co. (China) were all analytically pure grades, and were used without further purification. The analytical reagents butyl acrylate (BA), methacrylic acid (MAA), styrene (St) and octadecyl acrylate (ODA) were all purchased from Tianjing Chemical Reagent Factory (China) and were distilled under vacuum before use. Polymerisable surfactant was prepared in our laboratory [22].

\subsection{Synthesis of Polymerisable Surfactant (MT)}

1 mol Maleic anhydride and 1 mol Nonyl phenol ethoxylate were stirred in a melted state at $70^{\circ} \mathrm{C}$ for $3 \mathrm{~h}$. $\mathrm{NH}_{3} \cdot \mathrm{H}_{2} \mathrm{O}$ was then added dropwise to the reaction mixture to adjust the $\mathrm{pH}$ value of reaction system to 6 and thereafter the temperature was maintained at $90^{\circ} \mathrm{C}-95^{\circ} \mathrm{C}$ until the solution became transparent. After additional $2 \mathrm{~h}$, a kind of transparent solution with $35 \%$ solid content, that is, polymerisable surfactant (MT) was obtained by adding certain amount of distilled water.

\subsection{Preparation of Poly (BA-n-ODA) Seed Emulsion}

1.5 g polymerisable surfactant (MT) and distilled water were introduced into a $250 \mathrm{ml}$ four-necked flask equipped with a reflux condenser, a mechanical stirrer and a digital thermometer. Then $16 \mathrm{~g} \mathrm{BA}, 0.5 \mathrm{~g}$ MAA, $0.1 \mathrm{~g}$ $\mathrm{NaHSO}_{3}$ and $0.2 \mathrm{~g} \mathrm{ODA}$ were added into the flask. After additional $30 \mathrm{~min}$ equilibration at $70^{\circ} \mathrm{C}, 6 \mathrm{~g} \mathrm{5 \%}$ potassium persulfate aqueous solution was dropped into the flask in $1 \mathrm{~h}$, then the system was kept at $70^{\circ} \mathrm{C}$ with constant stirring for additional $2 \mathrm{~h}$.

\subsection{Seeded Emulsion Polymerization}

$0.2 \mathrm{~g} \mathrm{NaHSO}_{3}$ and $50 \mathrm{~g}$ water were added into the above-mentioned seed emulsion. Then the mixture of 16 $\mathrm{g} \mathrm{St}, 16 \mathrm{~g} \mathrm{BA}, 1.0 \mathrm{~g} \mathrm{MAA}$ and MPTS was dropped into the flask under starved-feed addition, and simultaneously $10 \mathrm{~g} \mathrm{5 \%}$ potassium persulfate aqueous solution was introduced slowly into the reaction system. The reaction was kept for another $2 \mathrm{~h}$ after the addition was completed. Then the obtained emulsion was cooled to room temperature. Finally, ammonia was adopted to adjust the $\mathrm{pH}$ value of emulsion in the range of $7-8$.

\subsection{Preparation of Silica Sol}

A calculated amount of tetraethyl orthosilicate (TEOS), water, hydrochloric acid, and ethanol was added into a three-neck flask and stirred until the mixture became uniform. The molar ratio of TEOS: water: hydrochloric acid: ethanol was 1:1:0.01:4. The hydrolyzation of TEOS mixture was carried out under continuous stirring for 48 $\mathrm{h}$ at ambient temperature, and then transparent viscous silica sol was obtained; its average particle size was $109.3 \mathrm{~nm}$.

\subsection{Preparation of Hybrid Films}

Silica sol of different concentration was premixed with core-shell emulsion and then the mixture was stirred at room temperature for $30 \mathrm{~min}$. The resulting emulsion was cast on a tetrafluoroethylene plate to allow them to dry at room temperature for 5 days, and then at $60^{\circ} \mathrm{C}$ for $12 \mathrm{~h}$. After demoulding, the films were kept into a desiccator to avoid moisture.

\subsection{Characterization}

The rheological properties of emulsions were analyzed in a TA Instrument $\left.{ }^{(}\right)$AR2000ex Rheometer. All measurements were carried out at $25^{\circ} \mathrm{C}$ using concentric cylinders geometry.

The tensile strength and elongation at break of the films were measured on a multifunctional electronic strength tester TS 2000-S (Scientific and Technological Limited Company of High Iron in Taiwan). Tensile test bars $\left(5 \times 70 \mathrm{~mm}^{2}\right)$ were cut from PASi films of $0.4-0.7$ $\mathrm{mm}$ thickness. The standard tensile test performed was 
an adaptation of ASTM 412-83, D 638-84, and D 882-83 methods.

Temperature dependence of dynamic mechanical properties was conducted using an America TA Q800 dynamic viscoelastometer at an operating frequency of $1 \mathrm{~Hz}$ from $-70^{\circ} \mathrm{C}$ to $150^{\circ} \mathrm{C}$ at a heating rate of $3^{\circ} \mathrm{C} \cdot \mathrm{min}^{-1}$.

The WAXD analysis of the samples was performed on Rigaku D/max-2200pc X-ray diffractometer (Bruker axs Co.) in the range of $2 \theta=5^{\circ}-45^{\circ}$. And the degree of crystallinity was accordingly calculated by the software.

Thermogravimetric analysis (TG) and differential thermogravimetry (DTG) were performed in an American TA Q500 thermal analyzer. Film samples about $10 \mathrm{mg}$ were placed in a platinum sample pan and heated from $20^{\circ} \mathrm{C}-600^{\circ} \mathrm{C}$ under $\mathrm{N}_{2}$ atmosphere, at a heating rate of $10^{\circ} \mathrm{C} \cdot \mathrm{min}^{-1}$.

\subsection{Paper Sheets Preparation and Characterization}

For each experiment, four $60 \mathrm{~g} \cdot \mathrm{m}^{-2}$ paper sheets for physical property testing were prepared according to TAPPI method T205. All paper samples were dried, conditioned (for $24 \mathrm{~h}$ before any physical testing) and tested in the standard environment $\left(22^{\circ} \mathrm{C} \pm 2{ }^{\circ} \mathrm{C}\right.$ and $50^{\circ} \mathrm{C} \pm 2 \%$ relative humidity).

Sizing efficiency was measured as Stöckigt sizing degree (JIS P 8122, JIS method 1979). The specimens of paper were placed on the surface of $2 \%$ ammonium thiocyanate $\left(\mathrm{NH}_{4} \mathrm{SCN}\right)$ solution; the temperature was maintained at $20^{\circ} \mathrm{C} \pm 1{ }^{\circ} \mathrm{C}$. Then a drop of $1 \%$ ferric chloride solution was dropped onto the surface of the specimen. Switch off timer when three red spots were detected, and the time was recorded as Stöckigt sizing time. For each test unit, five specimens with the felt side and five with the wire side were measured.

For each surface strength test unit 6 specimens (200 $\mathrm{mm} \times 15 \mathrm{~mm}$ ) were prepared, all tests were measured by IGT picking speed detector (Sichuan Changjiang Paper instrument co., ltd).

For each folding endurance test unit 10 specimens (15 $\mathrm{mm} \times 100 \mathrm{~mm}$ ) were prepared, all tests were performed on YQ-Z-31 vertical folding tester (Sichuan Changjiang Paper instrument co., Ltd.).

For each ring crushing strength test unit 10 specimens $(15 \mathrm{~mm} \times 120 \mathrm{~mm})$ were prepared, all tests were performed on DCP-KY3000 computer control compression tester (Sichuan Changjiang Paper instrument co., Ltd.).

\section{Results and Discussions}

\subsection{Rheological Behavior of Hybrid Emulsion}

The viscosities of core-shell emulsions with different silica sol concentration are plotted as a function of shear rate in Figure 1. It was obvious that the viscosity increased with increase of silica sol concentration at higher shear rate from $0.1 \mathrm{~s}^{-1}$ to $1000 \mathrm{~s}^{-1}$, indicating an enhanced interaction among emulsion particles.

However, the viscosity displayed irregular change especially when shear rate was lower than $0.1 \mathrm{~s}^{-1}$. The main reason was that temporary physical network structure maybe formed among silica sol and emulsion particles with the addition of silica sol, which can be destroyed by higher shear rate. And the irregular change in viscosity suggested that the physical network structure formed in the emulsion was not uniform.

It was also obvious that the viscosity decreased with increasing shear rate, all emulsions exhibited shear-thinning behavior, and the phenomena became more pronounced with increasing silica sol concentration. This means the internal networks formed between silica sol and emulsion particles are rearranged upon shear rate, the reduced viscosity can bring more convenience for coating process.

\subsection{Mechanical Properties}

The tensile strength and elongation at break of hybrid films with different silica sol concentration were shown in Figure 2. It was found that tensile strength increased with increasing silica sol concentration. In this system, silica sol acted as the crosslinker, crosslinking degree can be increased with the increase of silica sol content. Therefore interfacial interaction can be increased, resulting in higher tensile strength. However, when external force was big enough to destroy the intramolecular chemical bond, the tensile strength will have no relationship with crosslinking degree. That's why tensile strength almost kept constant when silica sol concentration was greater than $6 \mathrm{wt} \%$.

It was also found that elongation at break decreased

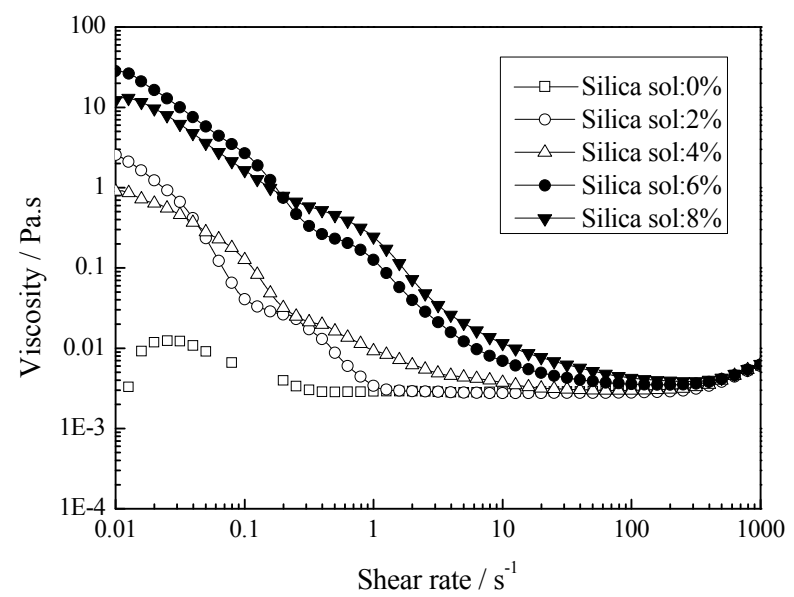

Figure 1. Viscosity versus shear rate curves with variation in silica sol concentration. 


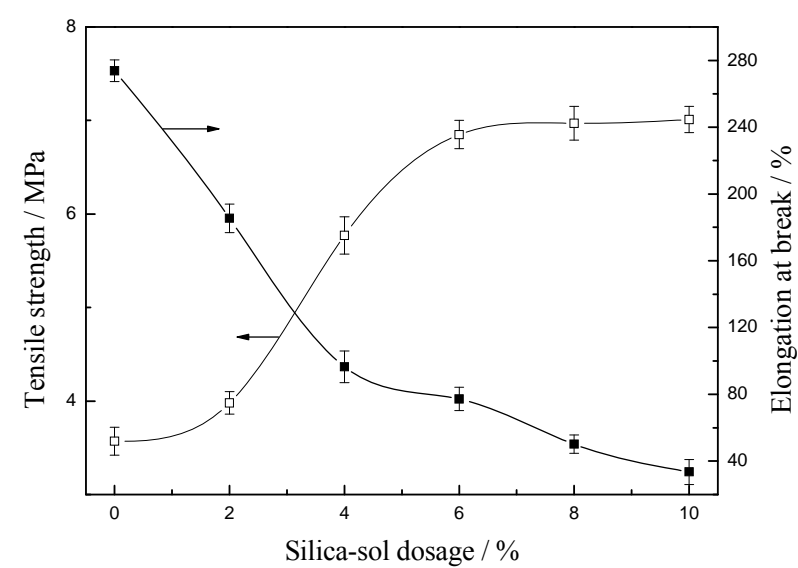

Figure 2. Effect of silica sol concentration on mechanical properties of the films.

gradually. Since the brittleness of hybrid films was enhanced simultaneously due to the increase of crosslinking degree, which lead to the decrease of elongation at break.

\subsection{Dynamic Mechanical Thermal Analysis}

Temperature dependence of storage modulus and loss factor $(\tan \delta$ ) with different silica sol concentration was presented in Figures 3 and 4, respectively. It was found that the storage modulus increased with silica sol addition, followed by decrease when silica sol concentration was greater than $6 \mathrm{wt} \%$. The increase of storage modulus can be attributed to the strong interfacial interaction between the organic polymer phase and the inorganic nano-silica phase. Similar phenomena were found in other researches [24]. However, the storage modulus decreased with further increase in silica sol concentration, which can be attributed to stress concentration and microphase separation induced by more crosslinking points in the system.

It was also found that the intensity of $\tan \delta$ peak decreased, indicating that the movement of polymer chain was restricted because of higher interfacial interaction [9]. By incorporation of silica sol into the polymer matrix, rigidity of the composite material can be improved, especially when there are strong interfacial interactions between organic and inorganic phases.

Furthermore, a slight $\mathrm{Tg}$ shift to lower temperature was observed when silica sol concentration was larger than $2 \mathrm{wt} \%$. Silica sol particles might act as "plasticizers", leading to slight lowered Tg values [16].

\subsection{Crystallinity}

WXRD curves of hybrid films with $0 \mathrm{wt} \%$ and $4 \mathrm{wt} \%$ silica sol were shown in Figure 5. The degree of crystallinity increased from $5.12 \%$ to $10.98 \%$ with $4 \mathrm{wt} \%$ silica sol addition, demonstrating that the rigidity of films can

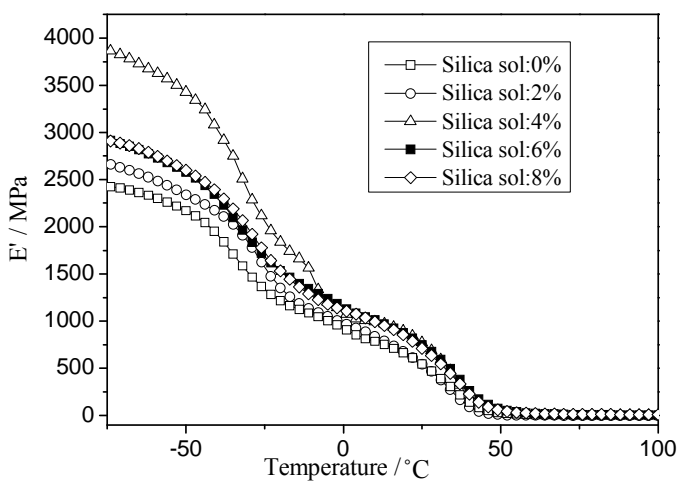

Figure 3. Temperature dependence of storage modulus with different silica sol concentration.

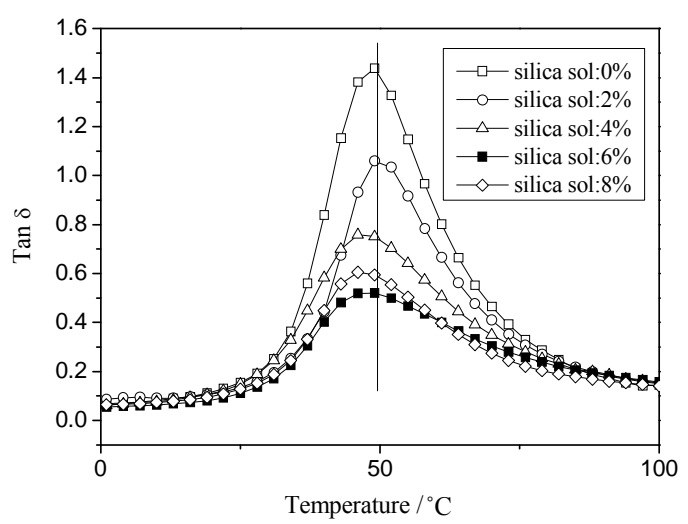

Figure 4. Temperature dependence of loss tangent $(\tan \delta)$ with different silica sol concentration.

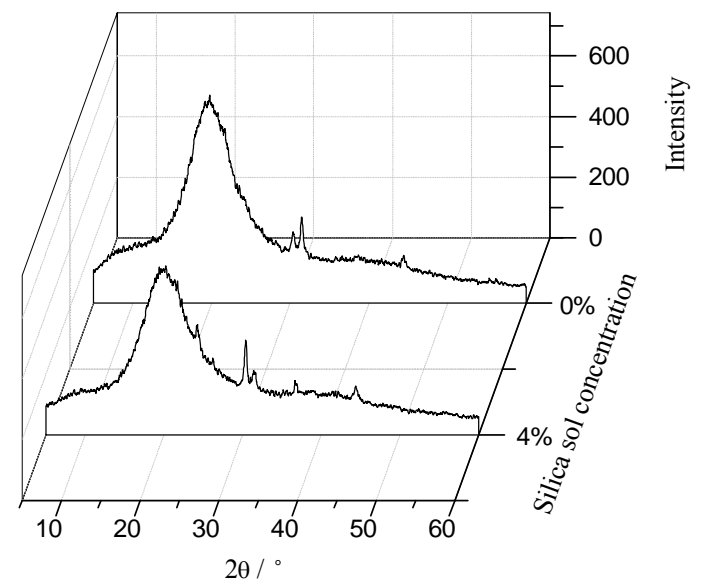

Figure 5. WXRD curves of hybrid films with different silica sol concentration.

be enhanced with increase of silica sol concentration.

\subsection{Thermal Stability of Hybrid Emulsion Films}

The TG and DTG curves of silica sol were shown in Figure 6. It was found that silica sol degraded in two steps: the first step $\left(<174^{\circ} \mathrm{C}\right)$ can be attributed to physi- 
cally adsorbed water on the surface of silica sol particles; while the second step in the range from $174^{\circ} \mathrm{C}$ to $650^{\circ} \mathrm{C}$ was due to the degradation of hydroxyl groups and ethoxy groups.

The TG and DTG curves of hybrid emulsion films with different silica sol concentration were simultaneously investigated, as shown in Figures $\mathbf{7}$ and 8, respectively. As silica sol was introduced, the thermal decomposition temperature increased from $325.5^{\circ} \mathrm{C}$ to $351.19^{\circ} \mathrm{C}$.

The nano-silica particles in the continuous polymer matrix endowed the materials with better thermal stability through enhanced interfacial interactions, and the effect is more pronounced with increasing silica sol concentration. Similar phenomena are found by other researches [24]. However, the decomposition temperature decreased from $351.19^{\circ} \mathrm{C}$ to $331.63^{\circ} \mathrm{C}$ when silica sol concentration was greater than $6 \mathrm{wt} \%$. This can be attributed to microphase separation among silica sol phase and silicon-acrylic phase. The measured char yields of hybrid films increased with increasing silica sol concentration.

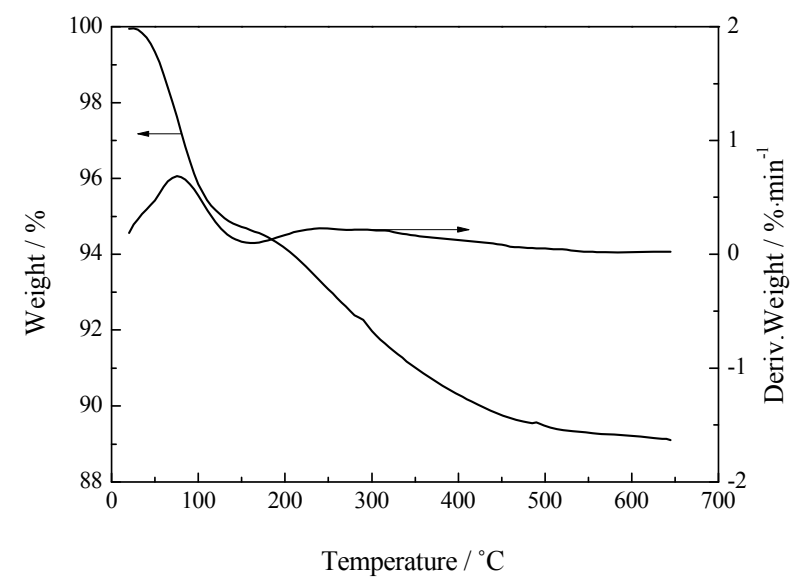

Figure 6. TG and DTG curves of silica sol.

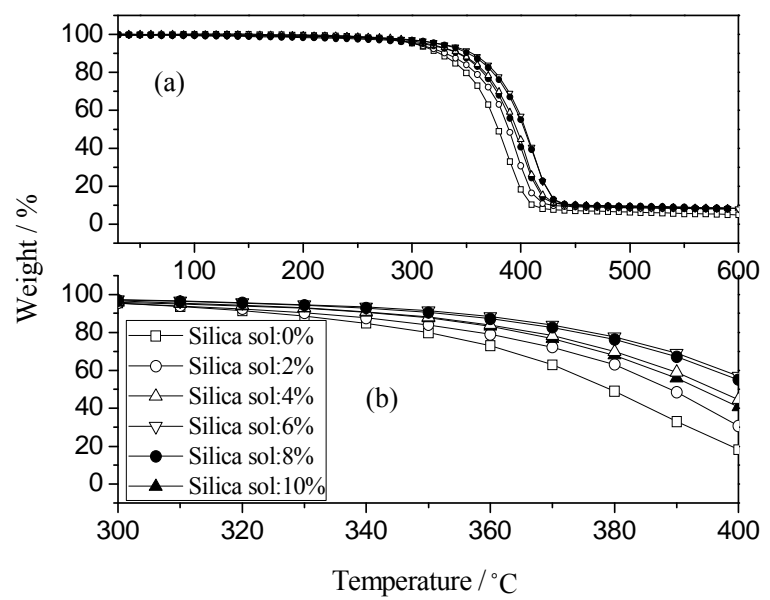

Figure 7. TG curves of hybrid films with different silica sol concentration.

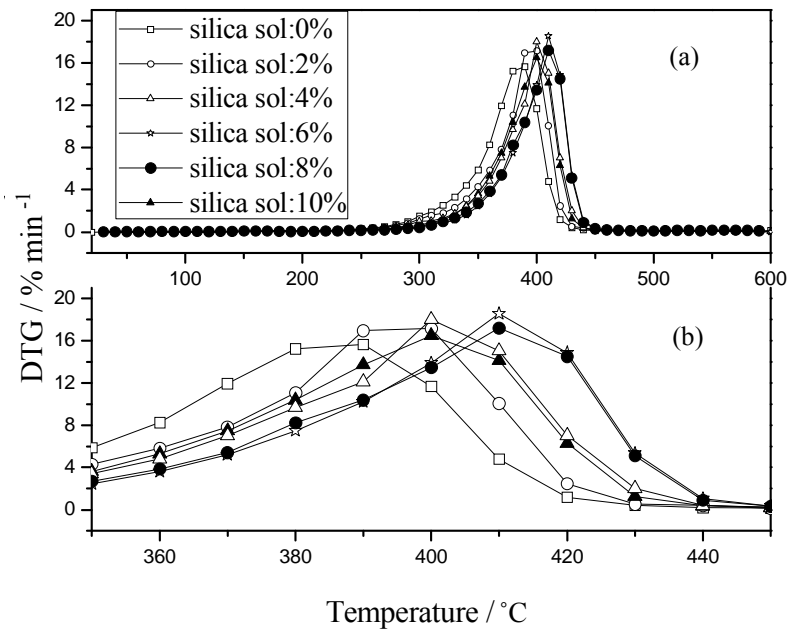

Figure 8. DTG curves of hybrid films with different silica sol concentration.

\subsection{Surface Sizing Properties of Hybrid Emulsions}

Effects of silica sol concentration on paper sizing degree, surface strength, folding endurance and ring crush strength were shown in Figures 9 and 10. It was found that Stockigt sizing time, surface strength, folding endurance and ring crush strength increased with certain amount of silica sol concentration. Since the introduction of nano-silica sol can enhance the interactions between polymer and fibers. However, different maximum silica sol concentrations were detected for different property parameters. Surface sizing degree decreased when silica sol concentration was greater than $6 \mathrm{wt} \%$, which can be due to the microphase separation as above-mentioned. While surface strength and ring crush strength reached maximum when silica sol concentration was $8 \mathrm{wt} \%$. Since surface strength and ring crush strength relied more on crosslinking and rigidity of paper. Compared with the influence of microphase sepearation, crosslinking degree played a more important role, that's why surface strength and ring crush strength kept increasing till the silica sol concentration reached $8 \mathrm{wt} \%$. However, brittleness of film increased simultaneously with increasing crosslinking degree, resulting in sharp decrease of folding strength just with $4 \mathrm{wt} \%$ silica sol.

\section{Conclusion}

In conclusion, the core-shell silicon-acrylic emulsions were endowed with pseudoplasticity with the addition of silica sol. With desirable amount of silica sol, the motion of polymer chains was highly restricted due to the strong interfacial interaction between the organic polymer phase and the inorganic silica phase. As result, tensile strength and thermal stability of emulsion films can be increased. 


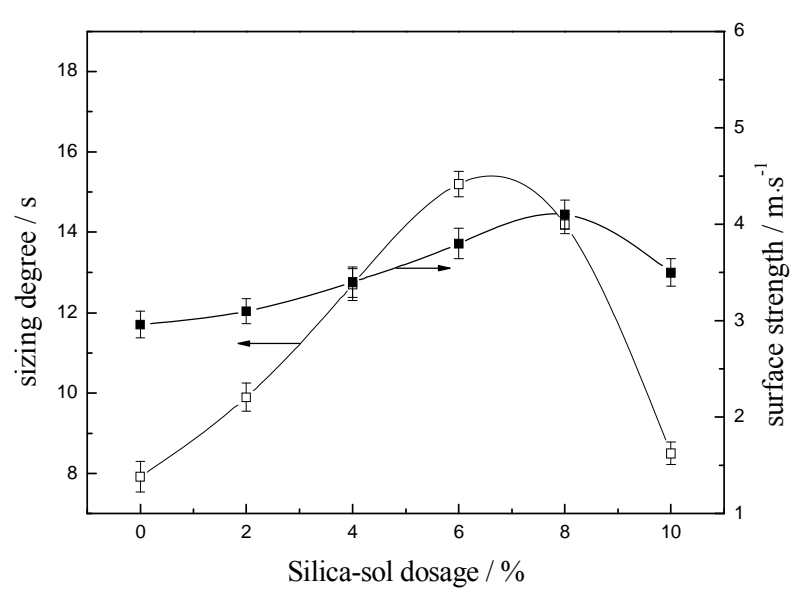

Figure 9. Effects of silica sol concentration on paper sizing degree and surface strength.

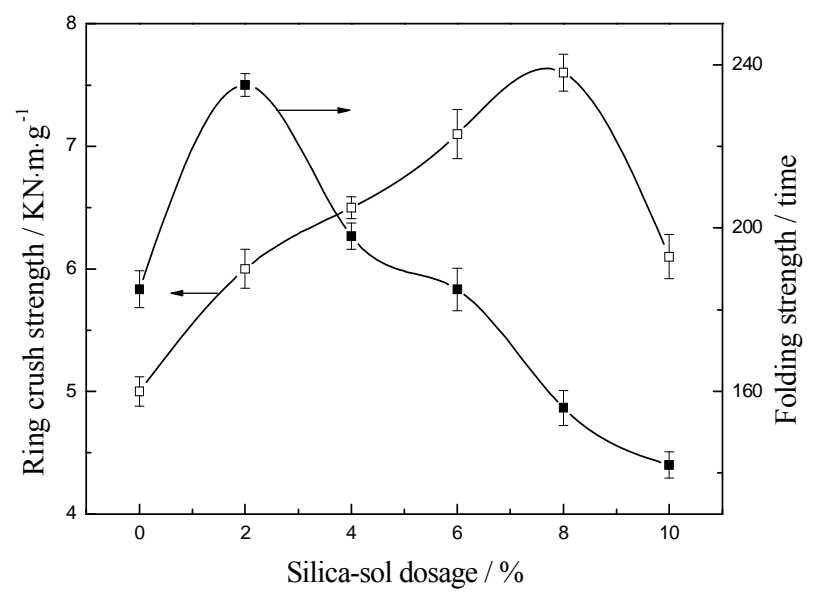

Figure 10. Effects of silica sol concentration on paper ring crush strength and folding strength.

Furthermore, the interactions among copolymer and fibers were enhanced with the addition of silica sol, the sized paper have higher sizing degree, ring crush strength, surface strength and folding strength. Therefore, silica sol can be utilized as a good cross-linking agent for polymer emulsions to improve their mechanical property and water resistance. Further study on the structure-property relationship of silicon-acrylic/silica sol emulsions will promote their application in the field of adhesive and coating.

\section{Acknowledgements}

The authors express sincere thanks to the National Natural Science Foundation of China (No. 50973057; 50673055), Natural Science Foundation of Shaanxi Province of China (No. 2010JK433 and No. 2009JQ2004) Foundation of Shaanxi University of Science \& Technology (ZX08-07, BJ09-18) for financial support.

\section{REFERENCES}

[1] X. Y. Xiao and C. C. Hao, "Preparation of Waterborne Epoxy Wcrylate/Silica Sol Hybrid Materials and Study of Their UV Curing Behavior," Colloids Surfaces A: Physicochemical and Engineering Aspects, Vol. 359, No. 1-3, 2010, pp. 82-87. doi:10.1016/j.colsurfa.2010.01.067

[2] M. Giulio, et al., "Hybrid Nanocomposites Containing Silica and PEO Segments: Preparation through DualCuring Process and Characterization," Polymer, Vol. 46, 2005, pp. 2872-2879. doi:10.1016/j.polymer.2005.02.045

[3] Y. Q. Fu and Q. Q. Ni, "Interaction of PMMA-Silica in PMMA-Silica Hybrids under Acid Catalyst and Catalyst-Lsee Conditions," Journal of Non-Crystalline solids, Vol. 351, No. 8-9, 2005, pp. 760-765. doi:10.1016/j.jnoncrysol.2005.01.052

[4] W.-J. Huang and W.-F. Lee, "Effect of Silane Coupling Agent on Swelling Behaviors and Mechanical Properties of Thermosensitive Hybrid Gels," Journal of Applied Polymer Science, Vol. 111, No. 4, 2009, pp. 2025-2034. doi:10.1002/app.29191

[5] K. R. Sunajadevi and S. Sugunan, "Preparation and Characterization of Nanocrystalline Transition Metal-Loaded Sulfated Titania through Sol-Gel Method," Materials Letters, Vol. 58, No. 26, 2004, pp. 3290-3296. doi:10.1016/j.matlet.2004.06.019

[6] L.-Y. Hong, Y.-S. Cho and D.-P. Kim, "Effect of Component Ratios on the Performance of UV Curing Organic/Inorganic Coating," Journal of Industrial Engineering Chemistry, Vol. 11, No. 2, 2005, pp. 275-279.

[7] M. E. L. Wouters, D. P. Wolfs, M. C. van der Linde, J. P. H. Hovens and A. H. A. Tinnemans, "Transparent UV Curable Antistatic Hybrid Coatings on Polycarbonate Prepared by the Sol-Gel Method," Progress in Organic Coatings, Vol. 51, No. 4, 2004, pp. 312-319. doi:10.1016/j.porgcoat.2004.07.020

[8] T. Zhang, K. Xi, H. Chen and X. H. Yu, "Synthesis and Properties of Self-Crosslinkable Polyurethane-Urea with Silsesquioxane Formation," Journal of Applied Polymer Science, Vol. 91, No. 1, 2004, pp. 190-195.

doi:10.1002/app.13212

[9] S. Patel, A. Bandyopadhyay, V. Vijayabaskar and A. K. Bhowmick, "Effect of Microstructure of Acrylic Copolymer/Terpolymer on the Properties of Silica Based Nanocomposites Prepared by Sol-Gel Technique," Polymer, Vol. 46, No. 19, 2005, pp. 8079-8090. doi:10.1016/j.polymer.2005.06.067

[10] J.-W. Ha, I. J. Park, S.-B. Lee and D.-K. Kim, "Preparation and Characterization of Core-Shell Particles Containing Perfluoroalkyl Acrylate in the Shell," Macromolecules, Vol. 35, No. 18, 2002, pp. 6811-6818. doi: $10.1021 / \mathrm{ma} 011692 \mathrm{u}$

[11] K.-H. Chung, "Effect of Silica Reinforcement on Natural Rubber and Butadiene Rubber Vulcanizates by a Sol-Gel Reaction with Tetraethoxysilane," Journal of Applied Polymer Science, Vol. 108, No. 6, 2008, pp. 3952-3959. doi:10.1002/app. 27921

[12] S.-S. Choi, "Influence of Storage Time and Temperature and Silane Coupling Agent on Bound Rubber Formation 
in Filled Dtyrene-Butadiene Rubber Compounds," Polymer Testing, Vol. 21, No. 2, 2002, pp. 201-208. doi:10.1016/S0142-9418(01)00071-X

[13] Y. L. Zhao and S. Perrier, "Synthesis of Poly(Methyl Acrylate) Grafted onto Silica Particles by Z-Supported RAFT Polymerization," Macromolecular Symposia, Vol. 248, No. 1, 2007, pp. 94-103. doi:10.1002/masy.200750210

[14] D. S. C. dos Anjos, E. C. V. Revoredo and A. Galembeck, "Silicone-Polyacrylate Chemical Compatibilization with Organosilanes," Polymer Engineering \& Science, Vol. 50, No. 3, 2010, pp. 606-612. doi:10.1002/pen.21504

[15] C. Y. Kan, X. Z. Kong, Q. Yuan and D. S. Liu, "Morphological Prediction and Its Application to the Synthesis of Polyacrylate/Polysiloxane Core/Shell Latex Particles," Journal of Applied Polymer Science, Vol. 80, No. 12, 2001, pp. 2251-2258. doi:10.1002/app.1329

[16] S. X. Li, A. Shah, A. J. Hsieh, R. Haghighat, S. S. Praveen, I. Mukherjee, E. Wei, Z. T. Zhang and Y. Wei, "Characterization of Poly(2-Hydroxyethyl MethacrylateSilica) Hybrid Materials with Different Silica Contents," Polymer, Vol. 48, No. 14, 2007, pp. 3982-3989. doi:10.1016/j.polymer.2007.05.025

[17] X. Z. Kong, C. Y. Kan and Q. Yuan, "Preparation of Polyacrylate-Polysiloxane Core-Shell Latex Particles," Polymers for Advanced Technologies, Vol. 7, No. 12, 1996, pp. 888-890. doi:10.1002/(SICI)1099-1581(199612)7:12<888::AID-P AT598>3.0.CO;2-5

[18] B. L. Liu, X. B. Deng, S. S. Cao, S. J. Li and R. Luo, "Preparation and Characterization of Core/Shell Particles with Siloxane in the Shell," Applied Surface Science, Vol. 252, No. 6, 2006, pp. 2235-2241. doi:10.1016/j.apsusc.2005.03.223

[19] T. Jesionowski, F. Ciesielczyk and A. Krysztafkiewicz, "Influence of Selected Alkoxysilanes on Dispersive Properties and Surface Chemistry of Spherical Silica Precipitated in Emulsion Media," Materials Chemistry and Physics, Vol. 119, No. 1-2, 2010, pp. 65-74. doi:10.1016/j.matchemphys.2009.07.034

[20] J.-S. Kang, C.-L. Yu and F.-A. Zhang, "Effect of Silane Modified $\mathrm{SiO}_{2}$ Particles on Poly(MMA-HEMA) SoapFree Emulsion Polymerization," Iranian Polymer Journal, Vol. 12, No. 12, 2009, pp. 927-935.

[21] Y. Q. Wang, Y. P. Li, R. Y. Zhang, L. Huang and W. W. $\mathrm{He}$, "Synthesis and Characterization of Nanosilica/Polyacrylate Composite Latex," Polymer Composites, Vol. 27, No. 3, 2006, pp. 282-288. doi:10.1002/pc.20200

[22] H. H. Wang, X. R. Li and J. Mou, "Synthesis, Morphology and Rheology of Core-Shell Silicone Acrylic Emulsion Stabilized with Polymerisable Surfactant," eXPRESS Polymer Letters, Vol. 4, No. 11, 2010, pp. 670-680. doi:10.3144/expresspolymlett.2010.82

[23] G. Q. Fei, H. H. Wang, X. R. Li and J. Mou, "Rheology, Mechanical, and Thermal Properties of Core-Shell Silicon-Acrylic Copolymer Emulsion Films and Its Application on Surface Sizing: Role of Silane Coupling Agent," Polymer Bulletin, Vol. 67, No. 6, 2011, pp. 1017-1028. doi:10.1007/s00289-011-0477-0

[24] S.-H. Huang, T.-M. Don, W.-C. Lai, C.-C. Chen and L.-P. Cheng, "Porous Structure and Thermal Stability of Photosensitive Silica/Polyimide Composites Prepared by SolGel Process," Journal of Applied Polymer Science, Vol. 114, No. 4, 2009, pp. 2019-2029. doi:10.1002/app.30790 